\title{
Wiki as a Teaching Tool
}

\author{
Kevin R. Parker \\ Idaho State University \\ Pocatello, Idaho, USA
}

\author{
Joseph T. Chao \\ Bowling Green State University \\ Bowling Green, Ohio, USA
}

parkerkr@isu.edu

\author{
jchao@bgsu.edu
}

\begin{abstract}
Wikis are one of many Web 2.0 components that can be used to enhance the learning process. A wiki is a web communication and collaboration tool that can be used to engage students in learning with others within a collaborative environment. This paper explains wiki usage, investigates its contribution to various learning paradigms, examines the current literature on wiki use in education, and suggests additional uses in teaching software engineering.
\end{abstract}

Keywords: wiki, Web 2.0, collaborative learning, information and communication technologies, computer-mediated communication, e-learning, pedagogy, education, constructivism.

\section{Introduction}

Wiki is a major component of Web 2.0, the emergent generation of web tools and applications (Adie, 2006). Web 2.0 has the potential to complement, enhance, and add new collaborative dimensions to the classroom. Web 2.0 technologies such as blogs, wikis, podcasts, and RSS feeds have been dubbed 'social software' because they are perceived as being especially connected, allowing users to develop Web content collaboratively and open to the public (Alexander, 2006). Social software offers a variety of unique and powerful information sharing and collaboration features, acting as cognitive reflection and amplification tools, and aiding the construction of meaning through the act of self-design of knowledge databases (Jonassen, Peck, \& Wilson, 1999). Wikis in particular actively involve learners in their own construction of knowledge (Boulos, Maramba, \& Wheeler, 2006). Social software helps to realize the original vision of the Web as a space in which anyone can participate (Schaffert, Gruber, \& Westenthaler, 2006).

Web 2.0 tools are characterized by ease of use and rapidity of deployment, making possible powerful information sharing and straightforward collaboration (Boulos et al., 2006). Further, these tools afford the added advantage of reducing the technical skill required to use their features, allowing users to focus on the information exchange and collaborative tasks themselves without the distraction of a difficult technological environment (Kirkpatrick, 2006). Such 'transparent tech-

Material published as part of this publication, either on-line or in print, is copyrighted by the Informing Science Institute. Permission to make digital or paper copy of part or all of these works for personal or classroom use is granted without fee provided that the copies are not made or distributed for profit or commercial advantage AND that copies 1) bear this notice in full and 2) give the full citation on the first page. It is permissible to abstract these works so long as credit is given. To copy in all other cases or to republish or to post on a server or to redistribute to lists requires specific permission and payment of a fee. Contact Publisher@InformingScience.org to request redistribution permission. nologies' (Wheeler, Kelly, \& Gale, 2005) let the user concentrate more on the learning task by 'seeing through' the technology with which they are interacting.

The term 'wiki' is derived from the Hawaiian phrase, wiki-wiki, which means quick. A wiki is a collaborative web site whose content can be edited by visitors to the site, allowing users to easily cre- 
ate and edit web pages collaboratively (Chao, 2007). In essence, a wiki is a simplification of the process of creating HTML web pages in combination with a system that records each individual change that occurs over time, so that at any time a page can be forced to revert to any of its previous states. A wiki may also provide tools that allow the user community to monitor the constantly changing state of the wiki and discuss the issues that emerge. Some wikis restrict access to a group of members, allowing only members to edit page content although everyone may view it. Others allow completely unrestricted access, allowing anyone to both edit and view content (Olson, 2006). Wikis can be used as a source of information and knowledge, as well as a tool for collaborative authoring. Wikis allow visitors to engage in dialog and share information among participants in group projects, or to engage in learning with each other by using wikis as a collaborative environment in which to construct their knowledge (Boulos et al., 2006).

This paper will focus on the use of wikis in the classroom, beginning with a brief look at learning approaches that can be furthered through wikis, followed by a review of the current state of wiki use in education. It will then consider additional uses of wikis in education, and conclude with a discussion of appropriate uses of wikis rather than blogs.

\section{Approaches to Learning}

Many of the papers that deal with wikis in education indicate how a wiki supports a particular approach to learning. The most commonly listed learning paradigms are the cooperative/collaborative learning paradigm and the constructivist paradigm, although others are referenced.

\section{Cooperative/Collaborative Paradigm}

As noted, wikis are characterized by a variety of unique and powerful information sharing and collaboration features. In cooperative learning, students work in heterogeneous groups to support the learning of their individual members. Cooperative learning leads to positive interdependence of group members, individual accountability, face-to-face interaction, and appropriate use of collaborative skills (Schaffert, Bischof, et al., 2006). Cooperative teams achieve higher levels of thought and retain information longer than students who do their work individually (Johnson and Johnson, 1986). The collaborative features of wikis make them particularly well suited for cooperative learning environments (Schaffert, Bischof, et al., 2006).

Wikis can be used to facilitate computer-supported collaborative learning, i.e., the development of collaboration by means of technology to augment education and research (Augar, Raitman, \& Zhou, 2004). This enhances peer interaction and group work, and facilitates sharing and distributing knowledge and expertise among a community of learners (Lipponen, 2002). Wikis enhance asynchronous communication and cooperative learning among students, and promote cooperation rather than competition (De Pedro et al., 2006).

Collaborative learning becomes even more powerful when it takes place in the context of a community of practice. A community of practice consists of people engaged in collective learning in a shared domain. Thus, learning becomes a collaborative process of a group. Wikis can serve as a knowledge platform for a community of practice where members of the community can share their knowledge with the group, put up interesting pieces of information, work together, discuss issues, etc. (Schaffert, Bischof, et al., 2006). Wikis are characterized by some of the elements fundamental to a successful community of practice, including a virtual presence, a variety of interactions, easy participation, valuable content, connections to a broader subject field, personal and community identity and interaction, democratic participation, and evolution over time (Schwartz, Clark, Cossarin, \& Rudolph, 2004). 


\section{Constructivist Paradigm}

Constructivism sees knowledge as well as meaning as constructed rather than given. Constructivism itself does not suggest a particular pedagogy, but rather describes how learning happens. Miers (2004) provides a fine summary of constructivism:

$[C]$ onstructivist learning should engage students in meaningful learning and ... the critical features are that the learning should be...

- Active and manipulative, engaging students in interactions and explorations with learning materials and provid[ing] opportunities for them to observe the results of their manipulations

- Constructive and reflective, enabling students to integrate new ideas with prior knowledge to make meaning and enable learning through reflection

- Intentional, providing opportunities for students to articulate their learning goals and monitor their progress in achieving them

- Authentic, challenging and real-world (or simulated), facilitating better understanding and transfer of learning to new situations

- Cooperative, collaborative, and conversational, providing students with opportunities to interact with each other to clarify and share ideas, to seek assistance, to negotiate problems, and discuss solutions. (p. 4)

In recent years, those involved in online learning have had a growing awareness of the benefits of constructivist online learning environments (Seitzinger, 2006). Hence, the recent interest in wikis in education. Constructivism is approached from a variety of perspectives in wiki research, including reflective activity and communal or social constructivism.

Reflective learning, one of the critical features of constructivism, refers to structured approaches that enable students to reflect upon their learning and to understand their own learning processes. Wikis are playing an increasing role in students' reflective learning, and enrich students' experience "beyond the mere contingent and often ephemeral details of each project, overlayering this experience with a more general and overarching, personally-constructed viewpoint on design processes, on how we experience and create the designed world in which each person lives and a conceptual framework that will enable them to quickly develop their understanding further" (Chen et al., 2005).

Wikis allow learners to participate in collaboratively building resources. An essential part of reflective learning is that learners should be encouraged to reflect on their knowledge and make it explicit. Wikis allow this reflection to be done collaboratively, moving closer to a fully social constructivist mode of learning. Because of their very low technological barriers yet very rich and flexible functionality, wikis afford the opportunity to offer collaborative, constructive learning more extensively in our educational environments (McMullin, 2005).

Social constructivists believe that we learn by social and communal activities. Meaning is shaped and knowledge constructed through discussion with peers and teachers, and through reflection (Higgs and McCarthy, 2005). The collaborative nature of wikis means that they enact knowledge building with and for others, with the focus being on the community rather than on the individual learner. Wikis are one of the success stories in the world of social constructivism_since they can be rapidly deployed and students can be very quickly operational (Notari, 2003).

\section{Other Approaches}

There are additional approaches to learning that are addressed in wiki literature. Yukawa (2005) examines the use of wikis in narrative analysis, which uses both text and online talk to construct a 
holistic view of the learning experience involving cognition, affect, and interaction. Schaffert, Bischof, et al. (2006) discuss many learning approaches, including cognitive apprenticeship, which is based on the knowledge and skill transfer in the traditional master-apprentice education. The collaborative aspect of wikis allows teachers and students to work closely together on a topic, e.g., writing a text or article, collecting information on a topic, etc., regardless of the whereabouts of students and teachers. In a broad sense, a wiki can be considered a learning object if it contains an educational purpose (Nash, 2005).

\section{Current State of Wikis in Education}

Although the wiki was introduced more than ten years ago, its use is relatively new in academia (Chao, 2007; Evans, 2006; Schaffert, Bischof, et al., 2006). Higher education has only recently begun to explore the potential educational value of wikis as a means to promote deeper learning and integration of learning experiences from both inside the classroom and out (Chen et al., 2005). Despite their potential impact on business, the wiki phenomenon, by and large, has not yet made it to the classroom, either as a research topic or as a teaching method (Evans, 2006). However, the popularity of wikis has begun to attract the attention of educators, who expect that wikis will facilitate not only communication but also the collaborative finding, shaping, and sharing of knowledge, all of which are essential properties in an educational context (Reinhold, 2006). As a consequence, papers related to wiki use in education have finally begun to appear in recent years.

A literature search reveals the current state of the wiki education. There are a variety of applications, primarily in writing assignments, group projects, and online/distance education, although innovative uses in other areas can be found as well.

\section{Lists of Uses}

There are several papers that, among their discussion of wikis, present a list of uses for wikis in the classroom, along with a discussion of each in most cases. Mader's site (2006b) focuses solely on wikis in education, citing uses such as simple webpage creation, project development with peer review, group authoring, tracking group projects, data collection, and class/instructor reviews. His online text (Mader, 2006a) contains writings by several authors discussing such topics as integrating a wiki in instruction, collaborative writing projects, group wiki projects, using wikis within course management systems, constructing science knowledge, and wiki-based collaboration and academic publishing. Fountain (2005) presents a survey of wiki use in education, and suggests several additional uses of wikis. Co-creating and co-monitoring projects are discussed, as is collaborative concept elaboration.

Duffy and Bruns (2006) list several possible educational uses of wikis:

- Students can use a wiki to develop research projects, with the wiki serving as ongoing documentation of their work.

- Students can add summaries of their thoughts from the prescribed readings, building a collaborative annotated bibliography on a wiki.

- A wiki can be used for publishing course resources like syllabi and handouts, and students can edit and comment on these directly for all to see.

- Teachers can use wikis as a knowledge base, enabling them to share reflections and thoughts regarding teaching practices, and allowing for versioning and documentation.

- Wikis can be used to map concepts. They are useful for brainstorming, and editing a given wiki topic can produce a linked network of resources.

- A wiki can be used as a presentation tool in place of conventional software, and students are able to directly comment on and revise the presentation content. 
- Wikis are tools for group authoring. Often group members collaborate on a document by emailing to each member of the group a file that each person edits on their computer, and some attempt is then made to coordinate the edits so that everyone's work is equally represented; using a wiki pulls the group members together and enables them to build and edit the document on a single, central wiki page.

Guzdial, Rick, and Kehoe (2001) recount how wikis, including their CoWeb, can be used for classroom activities such as distributing information, collaborative artifact creation, and discussion and review. Naish (2006) describes wiki use in learning as an information resource, a collaboration tool, a tool for building e-learning content, and as icebreakers. The concept of workflow learning in action is thoroughly discussed. Schaffert, Bischof, et al. (2006) suggest the use of wikis in project-based learning, collaborative story writing, and interdisciplinary and intercultural learning.

Tonkin (2005) identifies four different forms of educational wikis:

1. Single-user wikis allow an individual to collect and edit his or her own thoughts using a Web-based environment.

2. Lab book wikis allow students to keep notes online with the added benefit of allowing them to be peer reviewed and changed by fellow students.

3. Collaborative writing wikis can be used by a team for joint writing.

4. Knowledge base wikis provide a knowledge repository for a group.

Lamb (2004) points out that some faculty utilize wikis so that design teams can quickly and collaboratively build reference lists and outlines, brainstorm instructional strategies, and capture suggestions. Bergin (2002) suggests a variety of uses for wikis including student homepages, anonymous feedback, student-created FAQ, ideas related to the course, infrastructure hints, and discussions. Schwartz et al. (2004) survey twenty-four universities and report how wikis are being used. They report that most dealt with activities, events, or clubs rather than with curricular issues.

Wikipedia's (2006) School and University Projects page suggests uses of wikis in the classroom to provide students with exercises editing and publishing content on Wikipedia.

\section{Writing Assignments}

Perhaps the most common pedagogical application of wikis is supporting writing instruction (Lamb, 2004). Using a wiki as a writing tool maximizes the advantages of reflection, reviewing, publication, and of observing cumulative written results as they unfold (Fountain, 2005).

Lamb (2004) reports that a wiki called "Why Use Wikis to Teach Writing" lists a number of the medium's strengths for the teaching of writing skills:

- wikis stimulate writing ('fun' and 'wiki' are often associated);

- wikis provide a low-cost but effective communication and collaboration tool (with an emphasis on text rather than software);

- wikis promote the close reading, revision, and tracking of preliminary work;

- wikis discourage 'product oriented writing' while facilitating 'writing as a process'; and

- wikis ease students into writing for a wider audience

Barton (2004) lists some innovative uses for wikis in composition:

1. Any class project with a reference or encyclopedic format, such as instructions, user manuals, glossaries, etc. 
2. A class or group project with a bibliographic format that requires students to locate websites related to a topic, and then annotate, rank, and organize them.

3. A handbook or textbook. For example, students could build a guide to correct punctuation, which could be compiled and evaluated as a class, giving every student a stake in the project and benefiting each from the authoring process.

4. Any project that does not require individual authorship or protected documents.

Rick, Guzdial, Carroll, Holloway-Attaway and Walker (2002) studied two sections of an English Composition class, taught by the same instructor. The first section used CoWeb, a wiki-based tool, to complete various assignments while the comparison section performed the same activities, but worked in a threaded-discussion on-line environment similar to a Usenet newsgroup. In each rating category, the CoWeb section outperformed the comparison section, in most cases by a large statistically significant amount.

Forte and Bruckman (2006) discuss the writing-to-learn paradigm, focusing on how to engage students in collaborative writing activities. They investigate how to design wiki publishing tools and curricula to support learning among student authors, and suggest that collaborative publishing on a wiki offers an interesting model for creating authentic classroom writing activities and can be a powerful tool for constructing knowledge.

Byron (2005) discusses the uses of wikis in his distance learning symbolic logic class. Students were required to summarize various assigned readings and post them on the wiki, and the rest of the class was allowed to edit collaboratively those postings to improve both accuracy and completeness.

Hampel, Selke, and Vitt (2005) focus on collaborative writing methods and the requirements of tools used with special consideration of wikis. They then go on to describe the concrete realization of a fusion of semantic-spatial structuring techniques and collaborative writing, considering the integration of wiki techniques into virtual knowledge spaces.

Schaffert, Bischof, et al. (2006) discuss the concept of collaborative creative writing, in which a wiki serves as an interactive writing book, allowing students to collaboratively write an essay or story. Such collaboration offers numerous opportunities. For example, a story may have more than one ending, or it could even branch out like a tree based on different twists and conclusions. More artistically inclined students could supplement the story with illustrative figures or images.

Bruns and Humphreys (2005) describe how a wiki-based project was incorporated into a new media technologies course. Students developed the M/Cyclopedia (Media/Culture), a wiki-based encyclopedic collection of information on new media concepts and topics, using Wikipedia's MediaWiki. The wiki system was also used for student interactions, discussions, coordination, and tutorials outside of classes. The editing of each wiki subject was limited to students in the particular subject to facilitate student assessment. Lund and Smørdal (2006) discuss a similar project, in which technology is the same and the assignments are based on similar ideas of letting the learners co-construct subject entries in an encyclopedia.

Scardamalia and Bereiter (1994) speculate that one of the key drivers of collaborative writing may be dissatisfaction in interplay. If students do not like what they see, such as the approach taken by others, they may be more inclined to participate in order to propose an alternative approach. De Pedro et al. (2006) discuss one of the drawbacks of writing documents collaboratively. Students must be able to overcome their reluctance to allow others to see their unfinished working documents, and must be willing to let others contribute changes. 


\section{Project-based Learning}

Schwartz et al. (2004) point out that project-based learning is fairly common in various fields including music and languages. Projects play a large role in the context of educational environments because the project method is seen as a way to reach education goals. Wikis represent a very effective tool for project planning and documentation (Schaffert, Bischof, et al., 2006). When used for collaborative class projects, wikis allow students to meet virtually at their convenience and work on projects together (Byron, 2005). A geographically dispersed project team could use a wiki as a way of keeping in touch, sharing ideas and developing the project. Because all comments/ideas are consolidated on one webpage, a wiki creates a clearer picture of team direction than do individual email messages (Naish, 2006).

Fountain (2005) suggests several applications of a wiki in project integration work, including managing a long-term design process, problem solving, permitting constructive critique of pedagogical projects, allowing commentaries/critiques on project integration work, and cross class/course projects. Schaffert. Gruber, et al. (2006) suggest ways in which wikis can be useful in project knowledge management, including brainstorming and exchange of ideas, coordination of activities, coordination and records of meetings, and serving as a notepad for common information items. Chen et al. (2005) discuss the benefits of wikis in their design engineering group project, including enabling students to gather, organize, and share writing, photos, videos, presentations, and other digital creations.

De Pedro et al. (2006) collected a list of advantages and disadvantages of the use of wikis from the opinions of the teaching staff who administered projects related to innovation in teaching. A pedagogical challenge common in project-based courses is that students see what they have produced but they do not see what they have learned (Chen et al., 2005). Wikis alleviate this problem.

\section{Online/Distance Education}

A Sloan Consortium study (2006) shows a sharp increase in the number of students taking online courses, reporting that:

- Almost 3.2 million students took at least one online course during the fall 2005 term, a significant increase over the 2.3 million students reported the previous year.

- The more than 800,000 student increase is more than twice the growth recorded in any previous year.

Wikis are a useful tool for facilitating online learning groups (Augar et al., 2004). They can be used to support the dissemination of information, to enable the exchange of ideas, and to facilitate group interaction. Further, wikis can be used to create a set of documents that reflect the shared knowledge of the learning group (Augar et al., 2004).

Both Byron (2005) and Tsinakos (2006) discuss their use of wikis in distance learning classes, the former in a distance learning symbolic logic class and the latter as an environment for the formation of collaborative student models during distance education sessions. Icaza, Heredia, and Borch (2005) detail the use of a wiki in an online graduate course using a pedagogical approach called project oriented immersion learning. Students were immersed in the environment of a fictional online publishing house that hires them to develop e-books, tutorials, and websites online. Seitzinger (2006) provides a thorough discussion of the benefits of constructivist online learning environments.

Wang and Turner (2004) and Elrufaie and Turner (2005) point out several problems using the traditional wiki paradigm in the classroom: 
- All content is modifiable by any user. For example, the instructor may want to restrict modifiability of certain pages, such as a course syllabus or assignments.

- All content is public. The user may want to keep a newly created page private (not visible to others) until a certain point in its development, but wiki technology does not permit this.

- Simultaneous edits are allowed but not successful. In order to allow several users to edit the contents of a given page simultaneously, a page locking mechanism is necessary to prevent overriding each other.

- The wiki is forever evolving. When a class ends the instructor may wish to freeze the wiki pages into an historical artifact rather than letting it evolve without end, but most wikis do not provide this feature.

The authors extended the basic wiki paradigm to overcome the undesirable features listed above, and to better serve the needs of their online class.

\section{Other Applications of Wikis}

Zinn (2006), Schaffert, Bischof, et al. (2006), and Schaffert, Griber, et al. (2006) present research on semantic wikis, i.e., a combination of a wiki and Semantic Web technology. Zinn (2006) developed a semantic wiki to serve as a mathematical resource for learners and researchers, made up of semantically linked documents, definitions, theorems, lemmas, proofs, exercises, and over four hundred examples. Schaffert, Bischof, et al. (2006) and Schaffert, Griber, et al. (2006) discuss how semantic wikis can support learners in flexible learning environments.

Both Augar et al. (2006) and Naish (2006) mention the use of wikis as an icebreaker tool for online groupwork. They demonstrate how wiki technology can be used to enhance social interaction among students online as well as for the dissemination of information to the student body, for building information repositories, or for the collaborative production of documents.

Evans (2006) reports on a collaborative effort in which students in an XML class collaborate to write their own wiki textbook, thus learning the material more thoroughly than they would have using a traditional resource. O'Neill (2005) discusses the slides2wiki tool, which can be used to create a site where students may collaborate to create their own class notes, using the lecture slides as a starting point. This approach can result in high-quality lecture notes and can provide an instructor with valuable feedback on what students have understood. Hamer (2006) reports on the use of a contributing student approach using wikis in which students research topics and share the results with other students. Student contributions are peer assessed through wikis, and lectures become class discussions. Student feedback indicates that the approach improved communication skills, research techniques, and teamwork, but some topics were not covered as thoroughly as were others.

Both Wang et al. (2005) and Chang and Schallert (2005) investigate the use of wikis in 'English as a Second Language' courses. Honegger (2005) describes the dissemination of wikis in the German-speaking school community, Switzerland in particular. They found that simplicity, openness, and lack of structure facilitates wiki use in schools, while the lack of wiki servers, lack of instructor IT skills, lack of a WYSIWYG editor, and traditional instructors were the barriers to wiki use in schools.

Lamb (2004) describes various examples of wiki use outside the classroom. Placement centers can use wiki pages to store and organize content for job postings and career development. Wikis can be provided by the university to act as a sounding board so that students can voice opinions about university policies. 


\section{More Wiki Studies}

Guzdial, Ludovice, Realff, Morley, and Carroll (2002) report that although CoWeb, a wiki-based tool, has been used successfully in several courses in various disciplines, the tool has been unsuccessful in a variety of math, engineering and computer science courses. Their survey indicates that the causes for the lack of success include too much student competition, students too confused to post questions on CoWeb, and faculty opposition to student collaboration.

The case study performed by Raitman, Ngo, Augar and Zhou (2005) tests students' sense of security (identity) when using wikis for online collaboration. Two wikis were set up; one required user login and one remained anonymous. The results showed the students preferred a user login wiki since they felt more secure. The wiki with required user login had significantly higher usage (number of pages, number of edits, number of views, etc.) than the anonymous wiki. The secure environment gave students a sense of honor and trust in their research and collaboration that nurtured collaborative work for which they were confident in claiming ownership.

Reinhold (2006) proposes an extension to wiki functionality. Wiki structure and navigation can be used for finding specific information, relating articles, navigating from one topic to another, or moving on to supplementary, external information. Quick navigation between articles related to the same context is possible through on explicit links within articles or by means of manual topic or full text search. The author implemented a prototype system, WikiTrails, which extends basic wiki functionality using trails, or paths, and user navigation tracking to enable teachers and students to provide trails through wiki content. Each node in a trail represents a wiki page visited by a user, and has at most one incoming edge, representing the transition from the previous page, and one outgoing edge, representing the transition to the following page. The order of nodes inside a trail corresponds with the temporal order in which the pages were originally accessed. Trails serve as a guide through wiki content and provide for more efficient collaborative, interdisciplinary work, offering multiple views and structures on top of the same content.

Notari (2006) asserts that collaboration is less likely to be a success without proper guidance, such as a script. A collaboration script is a description of a pedagogical scenario with several distinct phases. A good script requires the task that students have to perform, the composition of their group, the way that the task is distributed within and among groups, the mode of interaction, and the timing of the phases.

\section{Additional Uses of Wikis}

As the above literature search indicates, wikis have experienced increasing popularity as teaching tools in recent years. Although wikis have been utilized in many areas of education, including composition, literature, distance education, philosophy, design engineering, symbolic logic, and mathematics, they have untapped potential in many other areas as well. For example, both the collaborative nature and the convenience features of the wiki make it an ideal tool for software project collaboration and communication.

Wiki use is increasing in the software development industry (Louridas, 2006), but wiki usage in student software project collaboration is not as common. Chao (2007) provides details about a pilot study in which wikis were used for student project development in a software engineering course. Students in the course were initially required only to maintain a group diary of individual and team activities, but they soon began to devise innovative ways of using wikis for project activities that were unanticipated by the instructor. In addition to group diaries, wikis were used for such software development activities as:

- Project planning. Student teams developed the project plan collaboratively using a wiki. At the end of each iteration, project plans were to be updated according to the iteration 
results. Wikis have the potential to serve as a good version control tool since wikis track change histories on all pages and provide convenient mechanism for comparing different versions of the document.

- Requirements management. User requirements were maintained on wikis. The requirements were assigned to student developers, and the estimates were published on wikis.

- Project tracking/progress reports. Student developers report their progress on assigned requirements. When a requirement is completed, the responsible developer records the actual hours spent.

- Test case management. For each requirement, acceptance test cases were created and published by the responsible students on wikis. Once the test cases were executed, the results were also reported on the wikis.

- Defect tracking. Instead of using a costly commercial defect-tracking tool that was not readily available, defect-tracking pages were created on wikis for defect reporting and fixing.

- Client notes. Client logs were created on wikis to record all client and developer communications so that they could be shared among team members.

- Developing user documentation. Since different parts of the software were developed by various student developers, end-user documentation was created collaboratively by the whole team on wikis.

As can be seen from Chao's experience, there are a number of innovative ways in which wikis can augment collaborative work. With a little ingenuity, there are limitless ways in which wikis can enhance the learning process.

\section{Wiki or Blog}

Wikis are often compared to blogs because they are both characterized by extremely easy publishing capabilities. They both appeared about the same time, a little more than a decade ago, and both offer an easy publishing tool for disseminating information as well as getting feedback to and from the public. Early wikis were intended for multiple users to create knowledge repositories, while blogs were intended for writing personal diaries. Although they are different in many ways, the distinctions between them are subtle because they are converging in functionality.

There are a number of noteworthy differences between wikis and blogs, among them being the way they organize their information, and the number of contributors and what the contributors intend to achieve (Doyle, 2006).

- Wikis are designed for collaborative authoring by everyone while blogs are more personal and generally written by a single author. If a wiki has only one author, the differences are not as obvious though still significant and important, as can be seen from the following points. Further, there are valid uses for single-author wikis, such as posting explicit operational instructions from a user (Keairns, 2006).

- Wikis typically organize information into topics while blogs organize information in reverse chronological order. Since they are reverse chronologically ordered, information in blogs is more of a historical record and rarely changes. On the other hand, topics in wikis are expected to evolve and often expand into something of a permanent knowledge base.

- The reverse chronological order of blogs makes it difficult to find all postings on a particular topic, and to browse through all postings on that topic. On the other hand, wikis do not show as easily when information was documented or in what order, but it does show what information is related and make it easy to browse (Woolf, 2006). 
- Wikis receive feedback by allowing the public to edit topics directly, while blogs provide a mechanism for reader comments. The contents in blogs belong to the owner.

- Wikis encourage knowledge sharing around topics while blogs are a sharing of spontaneous thoughts.

- Blogs are a better communication tool for disseminating information to people and for enabling feedback while keeping the original text intact. Wikis are better when information is intended to be modified and enhanced as part of a collaborative effort (Mader, 2006c).

\section{Conclusion}

Wikis and other emergent technologies are beginning to fill a gaping void in existing practice (Lamb, 2004). They enable extremely rich, flexible collaborations that have positive psychological consequences for their participants and powerful competitive ones for their organizations (Evans and Wolf, 2005). Collaborative creativity promises to be a key business skill in upcoming years. Educational institutions can offer immense value to their students by familiarizing them with the simple technologies that make collaborative networks possible. Today's students will not only manage business innovations of the future, but in many cases will drive them. Rather than being limited to today's skills, students must learn the skills of the future. Educators need to teach what wikis and other social software may mean to business, not just as a phenomenon, but also as a skill (Evans, 2006). By incorporating wikis into the classroom, educators can better prepare students to make innovative uses of collaborative software tools.

\section{References}

Adie, C. (2006). Report of the information services working group on collaborative tools. Retrieved November 2006 from http://www.is.ed.ac.uk/content/1/c4/10/46/CollaborativeToolsAndWeb2\%200.pdf

Alexander, B. (2006). Web 2.0: A new wave of innovation for teaching and learning? Educause Review, 41(2) (March/April). Retrieved November 2006 from http://www.educause.edu/ir/library/pdf/ERM0621.pdf

Augar, N., Raitman, R. \& Zhou, W. (2004). Teaching and learning online with wikis. Proceedings of the 21 st Australasian Society for Computers in Learning in Tertiary Education (ASCILITE) Conference, Perth: December 5-8, 95-104. Retrieved November 2006 from http://www.ascilite.org.au/conferences/perth04/procs/pdf/augar.pdf

Barton, M. (2004). Embrace the wiki way! Retrieved November 2006 from http://www.mattbarton.net/tikiwiki/tiki-print article.php?articleId=4

Bergin, J. (2002). Teaching on the wiki web. Proceedings of the 7th Annual Conference on Innovation and Technology in Computer Science Education, ITICSE'02, Aarhus, Denmark: June 24-26, 195. Retrieved November 2006 from http://portal.acm.org/citation.cfm?id=637610.544473

Boulos, M.N.K., Maramba, I., \& Wheeler, S. (2006). Wikis, blogs and podcasts: A new generation of Webbased tools for virtual collaborative clinical practice and education, BMC Medical Education, 6(41). Retrieved November 2006 from http://www.biomedcentral.com/content/pdf/1472-6920-6-41.pdf

Bruns, A. \& Humphreys, S. (2005). Wikis in teaching and assessment: The M/Cyclopedia project. Proceedings of the 2005 International Symposium on Wikis, San Diego, CA, U.S.A.: October 16-18, 2532. Retrieved November 2006 from http://snurb.info/files/Wikis\%20in\%20Teaching\%20and\%20Assessment.pdf

Byron, M. (2005). Teaching with Tiki. Teaching Philosophy, 28(2), 108-113.

Chang, Y.-F. \& Schallert, D.L. (2005). The design for a collaborative system of English as foreign language: Composition writing of senior high school students in Taiwan. Proceedings of the Fifth IEEE International Conference on Advanced Learning Technologies (ICALT'05), Kaohsiung, Taiwan: July 
5-8, 774-775. Retrieved November 2006 from

http://portal.acm.org/citation.cfm?id=1078028.1078756\&coll=\&dl=ACM\&CFID=15151515\&CFTOK $\underline{\mathrm{EN}}=6184618$

Chao, J. (2007). Student project collaboration using Wikis. Proceedings of the 20th Conference on Software Engineering Education and Training (CSEE\&T 2007), Dublin, Ireland: July 3-5. Manuscript accepted for publication.

Chen, H.L., Cannon, D., Gabrio, J. Leifer, L. Toye, G. \& Bailey, T. (2005). Using wikis and weblogs to support reflective learning in an introductory engineering design course. Proceedings of the 2005 American Society for Engineering Education Annual Conference \& Exposition, Portland, Oregon: June 12-15. Retrieved November 2006 from http://riee.stevens.edu/fileadmin/riee/pdf/ASEE2005 Paper Wikis and Weblogs.pdf

De Pedro, X., Rieradevall, M., López, P., Sant, D., Piñol, J., Núñez, L., et al. (2006). Writing documents collaboratively in Higher education (I): Qualitative results from a 2-year project study. Congreso Internacional de Docencia Universitaria e Innovación (International Congress of University Teaching and Innovation), Barcelona: July 5-7. Retrieved November 2006 from http://uniwiki.ourproject.org/tiki-download_wiki_attachment.php?attId=98\&page=UniwikiCongressos

Doyle, B. (2006). When to wiki, when to blog. Retrieved November 2006 from http://www.econtentmag.com/Articles/ArticlePrint.aspx?ArticleID=16900

Duffy, P. \& Bruns, A. (2006). The use of blogs, wikis and RSS in education: A conversation of possibilities. Proceedings of the Online Learning and Teaching Conference 2006, Brisbane: September 26. Retrieved November 2006 from https://olt.qut.edu.au/udf/OLT2006/gen/static/papers/Duffy_OLT2006 paper.pdf

Elrufaie, E. \& Turner, D. (2005). A Wiki Paradigm for use in IT courses. Proceedings of the International Conference on Information Technology: Coding and Computing (ITCC'05), Las Vegas, Nevada, USA: April 4-6, 770-771. Retrieved November 2006 from http://www.csci.csusb.edu/turner/papers/harith_itcc_2005.doc

Evans, P. (2006). The wiki factor. BizEd, January/February, 28-32. Retrieved November 2006 from http://www.aacsb.edu/publications/Archives/JanFeb06/p28-33.pdf

Evans, P. \& Wolf, B. (2005). Collaboration rules. Harvard Business Review, July-Aug, 83(7): 96-104. Retrieved November 2006 from http://custom.hbsp.com/b02/en/implicit/viewFileNavBeanImplicit.jhtm

Forte, A. \& Bruckman, A. (2006). From wikipedia to the classroom: Exploring online publication and learning. Proceedings of the 7th International Conference on Learning Sciences, Bloomington, Indiana: June 27-July 1, 182-188. Retrieved November 2006 from http://wwwstatic.cc.gatech.edu/ asb/papers/forte-bruckman-icls06.pdf

Fountain, R. (2005). Wiki pedagogy. Dossiers technopédagogiques. Retrieved November 2006 from http://profetic.org/dossiers/article.php3?id article $=969$

Guzdial, M., Ludovice, P., Realff, M., Morley, T., \& Carroll, K. (2002). When collaboration doesn't work. Proceedings of the International Conference of the Learning Sciences, Seattle, Washington: October 23-26, 125-130. Retrieved November 2006 from http://coweb.cc.gatech.edu:8888/csl/uploads/24/CMCI-ICLS-final.pdf

Guzdial, M., Rick, J., \& Kehoe, C. (2001). Beyond adoption to invention: Teacher-created collaborative activities in higher education. Journal of the Learning Sciences, 10(3), 265-279. Retrieved November 2006 from http://coweb.cc.gatech.edu:8888/csl/uploads/24/CoWeb-final-Jan01.pdf

Hamer, J. (2006). Some experiences with the "contributing student approach". Proceedings of the 11th Annual SIGCSE Conference on Innovation and Technology in Computer Science Education (ITiCSE'06), Bologna, Italy: June 26-28, 68-72. Retrieved November 2006 from http://portal.acm.org/citation.cfm?id=1140123.1140145 
Hampel, T., Selke, H., \& Vitt, S. (2005). Deployment of simple user-centered collaborative technologies in educational institutions - Experiences and requirements. Proceedings of the 14th IEEE International Workshops on Enabling Technologies: Infrastructure for Collaborative Enterprise (WETICE'05), Linköping, Sweden: June 13-15, 207-214. Retrieved November 2006 from http://portal.acm.org/citation.cfm?id=1106781.1107281

Higgs, B. \& McCarthy, M. (2005). Active learning-from lecture theatre to field-work. In S. Moore, G. O'Neill, \& B. McMullin (Eds.), Emerging issues in the practice of university learning and teaching (pp. 37-44). Dublin: AISHE. Retrieved November 2006 from http://www.aishe.org/readings/20051/higgs-mccarty-Active_Learning_from_Lecture Theatre to_Field-work.pdf

Honegger, B.D. (2005). Wikis - a rapidly growing phenomenon in the German-speaking school community. Proceedings of the 2005 International Symposium on Wikis, San Diego, CA, USA: October 1618, 113-116. Retrieved November 2006 from http://www.wikisym.org/ws2005/proceedings/paper$\underline{10 . p d f}$

Icaza, J.I., Heredia, Y., \& Borch, O. (2005). Project oriented immersion learning: Method and results. Proceedings of ITHET 6th Annual International Conference, Juan Dolio, Dominican Republic: July 7-9, T4A7-T4A11. Retrieved November 2006 from http://fie.engrng.pitt.edu/ithet2005/papers/2087.pdf

Johnson, R. T., \& Johnson, D. W. (1986). Action research: Cooperative learning in the science classroom. Science and Children, 24, 31-32.

Jonassen, D.H., Peck, K.L., \& Wilson, B.G. (1999). Learning with technology: A constructivist perspective. Columbus, OH: Prentice Hall.

Keairns, B. (2006, May). Enterprise 2.0 and the debate about technology and control. Startup Spot. Retrieved March 2007 from http://www.startupspot.com/briankeairns/2006/05/index.html

Kirkpatrick, M. (2006). The flu wiki: A serious application of new web tools. Retrieved November 2006 from http://marshallk.blogspot.com/2005/07/flu-wiki-serious-applicationof-new.html

Lamb, B. (2004). Wide open spaces: Wikis, ready or not. EDUCAUSE Review, 39(5) (September/October), 36-48. Retrieved November 2006 from http://www.educause.edu/pub/er/erm04/erm0452.asp?bhcp=1

Lipponen, L. (2002). Exploring foundations for computer-supported collaborative learning. Proceedings of the Computer-supported Collaborative Learning Conference 2002, Boulder, CO: Jan 7-11, 72-81. Retrieved November 2006 from http://newmedia.colorado.edu/cscl/31.pdf

Louridas, P. (2006). Using wikis in software development. IEEE Software, 23(2), 88-91. Retrieved November 2006 from http://ieeexplore.ieee.org/Xplore/login.jsp?url=/iel5/52/33727/01605183.pdf

Lund, A. \& Smørdal, O. (2006). Is there a space for the teacher in a wiki? Proceedings of the 2006 International Symposium on Wikis, Odense, Denmark: August 21-23, 37-46. Retrieved November 2006 from http://www.wikisym.org/ws2006/proceedings/p37.pdf

Mader, S. (Ed.) (2006a). Using wiki in education, the book. Retrieved November 2006 from http://www.wikiineducation.com

Mader, S. (2006b). Ways to use wiki in education. Retrieved November 2006 from http://www.wikiineducation.com/display/ikiw/Ways+to+use+wiki+in+education

Mader, S. (2006c) Wiki vs. Blog. Retrieved November 2006 from http://www.businessblogwire.com/2006/03/stewart_mader_wiki_vs blog.html

McMullin, B. (2005) Putting the learning back into learning technology. In S. Moore, G. O’Neill, \& B. McMullin (Eds.), Emerging issues in the practice of university learning and teaching (pp. 67-76). Dublin: AISHE. Retrieved November 2006 from http://www.aishe.org/readings/2005-1/mcmullinD01-M10-2004.pdf

Miers, J. (2004). BELTS or Braces? Technology School of the Future. Retrieved November 2006 from http://www.tsof.edu.au/research/Reports04/miers.asp 
Naish, R. (2006). Can wikis be useful for learning? e.learning Age. Retrieved November 2006 from http://www.qiconcepts.co.uk/pdf/Can\%20Wikis\%20be\%20useful\%20for\%20learning.pdf

Nash, S. (2005). Learning Objects, Learning Object Repositories, and Learning Theory: Preliminary Best Practices for Online Courses. Interdisciplinary Journal of Knowledge and Learning Objects, 1, 217 228. Retrieved March 2007 from http://www.ijklo.org/Volume1/v1p217-228Nash.pdf

Notari, M. (2003). Scripting strategies in computer supported collaborative learning environments. Unpublished master thesis, TECFA, FPSE, University of Geneva.

Notari, M. (2006). How to use a wiki in education: Wiki based effective constructive learning. Proceedings of the 2006 International Symposium on Wikis, Odense, Denmark: August 21-23, 131-132. Retrieved November 2006 from http://www.wikisym.org/ws2006/proceedings/p131.pdf

Olson, G. (2006) New tools for learning. Retrieved November 2006 from http://faculty.eicc.edu/golson/tools.htm

O'Neill, M.E. (2005). Automated use of a wiki for collaborative lecture notes. Proceedings of the 36th SIGCSE Technical Symposium on Computer Science Education, St. Louis, Missouri, USA: February 23-27, 267-271. Retrieved November 2006 from http://portal.acm.org/citation.cfm?id=1047440

Raitman, R., Ngo, L., Augar, N., \& Zhou, W. (2005). Security in the online e-learning environment. Proceedings of the Fifth IEEE International Conference on Advanced Learning Technologies (ICALT'05), Kaohsiung, Taiwan: July 5-8, 702-706. Retrieved November 2006 from http://ieeexplore.ieee.org/iel5/10084/32317/01508795.pdf?arnumber=1508795

Reinhold, S. (2006). WikiTrails: Augmenting wiki structure for collaborative, interdisciplinary learning. Proceedings of the 2006 International Symposium on Wikis, Odense, Denmark: August 21-23, 47-58. Retrieved November 2006 from http://www.wikisym.org/ws2006/proceedings/p47.pdf

Rick, J., Guzdial, M., Carroll, K., Holloway-Attaway, L. \& Walker, B. (2002). Collaborative learning at low cost: CoWeb use in English composition. Proceedings of Computer Support for Collaborative Learning Conference, Boulder, CO, USA: January 7-11, 435-442. Retrieved November 2006 from http://coweb.cc.gatech.edu:8888/cs1/uploads/24/CoWebInEnglish-CSCL2002.pdf

Scardamalia, M., \& Bereiter, C. (1994). Computer support for knowledge-building communities. [Electronic version]. Journal of the Learning Sciences, 3(3), 265-283. Retrieved November 2006 from http://carbon.cudenver.edu/ bwilson/building.html

Schaffert, S., Bischof, D., Buerger, T., Gruber, A., Hilzensauer, W. \& Schaffert, S. (2006). Learning with semantic wikis. Proceedings of the First Workshop on Semantic Wikis - From Wiki To Semantics (SemWiki2006), Budva, Montenegro: June 11-14, 109-123. Retrieved November 2006 from http://www.wastl.net/download/paper/Schaffert06_SemWikiLearning.pdf

Schaffert, S., Gruber, A. \& Westenthaler, R. (2006). A semantic wiki for collaborative knowledge formation. In S. Reich, G. Güntner, T. Pellegrini, A. \& Wahler (Eds.): Semantic Content Engineering, Austria: Trauner Verlag. Retrieved November 2006 from http://www.salzburgresearch.at/research/gfx/SemWikiForCollKnowForm_20060120.pdf

Schwartz, L., Clark, S., Cossarin, M. \& Rudolph, J. (2004). Educational wikis: Features and selection criteria. International Review of Research in Open and Distance Learning, 5(1). Retrieved November 2006 from http://www.irrodl.org/index.php/irrodl/article/view/163/692

Seitzinger, J. (2006). Be constructive: Blogs, podcasts, and wikis as constructivist learning tools. Learning Solutions e-Magazine. Retrieved November 2006 from http://www.elearningguild.com/pdf/2/073106DES.pdf

Sloan Consortium. (2006). Making the grade: Online education in the United States, 2006. Retrieved November 2006 from http://www.sloan-c.org/publications/survey/survey06.asp

Tonkin, E. (2005). Making the case for a wiki. Ariadne, Issue 42, January. Retrieved November 2006 from http://www.ariadne.ac.uk/issue42/tonkin/ 
Tsinakos, A.A. (2006). Collaborative student modelling- A new perspective using wiki. WSEAS Transactions on Advances in Engineering Education, 3(6), June, 475-481. Retrieved November 2006 from http://de.teikav.edu.gr/tsinakos/pdf/TRANS tsinakos.pdf

Wang, C. \& Turner, D. (2004). Extending the wiki paradigm for use in the classroom. Proceedings of the International Conference on Information Technology (ITCC 2004), Las Vegas, Nevada, USA: April $5-$ 7, 255-259. Retrieved November 2006 from http://ieeexplore.ieee.org/iel5/9035/28682/01286462.pdf

Wang, H.-C., Lu, C.-H., Yang, J.-Y., Hu, H.-W., Chiou, G.-F., Chiang, Y.-T., et al. (2005). An empirical exploration of using wiki in an English as a second language course. Proceedings of the Fifth IEEE International Conference on Advanced Learning Technologies (ICALT'05), Kaohsiung, Taiwan: July 58, 155-157. Retrieved November 2006 from http://ieeexplore.ieee.org/iel5/10084/32317/01508634.pdf?arnumber=1508634

Wheeler, S., Kelly P., \& Gale, K. (2005). The influence of online problem-based learning on teachers' professional practice and identity. ALT-J 2005, 13(2):125-137.

Wikipedia. (2006). School and university projects. Retrieved November 2006 from http://en.wikipedia.org/wiki/Wikipedia:School_and_university_projects

Woolf, B. (2006). Wiki vs. Blog. IBM developerWorks. Retrieved November 2006 from http://www03.ibm.com/developerworks/wikis/display/woolf/Wiki+vs.+Blog

Yukawa, J. (2005). Story-lines: A case study of online learning using narrative analysis. In T. Koschmann, D. Suthers \& T. W. Chan (Eds.), Computer Supported Collaborative Learning 2005: The Next 10 Year (pp. 732-736). Mahwah, NJ: Lawrence Erlbaum Associates. Retrieved November 2006 from http://lilt.ics.hawaii.edu/lilt/papers/2005/Yukawa-CSCL-2005.pdf

Zinn, C. (2006). Bootstrapping a semantic wiki application for learning mathematics. International Conference on Semantics - Semantics 2006, Vienna, Austria: November 27-29. Retrieved November 2006 from http://www-ags.dfki.uni-sb.de/ zinn/Publications/semantics2006.pdf

\section{Biographies}

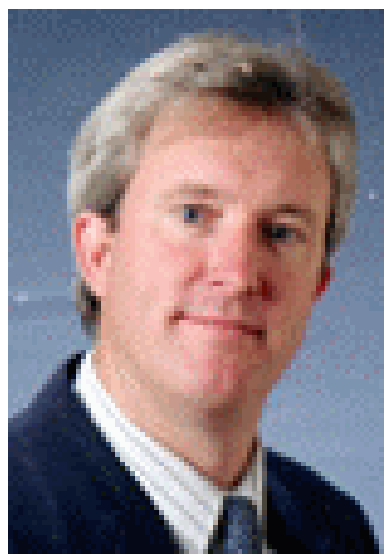

Dr. Kevin R. Parker is a Professor of Computer Information Systems at Idaho State University, having previously held an academic appointment at Saint Louis University. He has taught both computer science and information systems courses over the course of his fifteen years in academia. Dr. Parker's research interests include competitive intelligence, knowledge management, the Semantic Web, and information assurance. He has published in such journals as Journal of Information Technology Education, Journal of Information Systems Education, and Communications of the AIS. Dr. Parker's teaching interests include web development technologies, programming languages, data structures, and database management systems. Dr. Parker holds a B.A. in Computer Science from the University of Texas at Austin (1982), an M.S. in Computer Science from Texas Tech University (1991), and a Ph.D. in Management Information Systems from Texas Tech University (1995). 


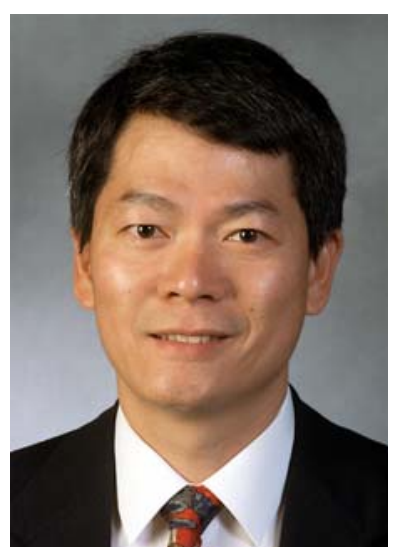

Dr. Joseph T. Chao has taught courses in all aspects of the software development lifecycle including programming, systems analysis and design, database systems, usability engineering, software engineering, and agile software development at Bowling Green State University. Prior to entering academia, Dr. Chao has seven years of industry experience in software development, including three years as Director of Software Development. His research focus is on software engineering with special interests in agile software development, programming languages, and object-oriented analysis and design. He has published in such journals as Journal of Information Technology Education, International Journal of Knowledge and Learning, Academe: Bulletin of the American Association of University Professors, and Journal of Manufacturing Systems. Dr. Chao holds an M.S. in Operations Research from Case Western Reserve University and a Ph.D. in Industrial and Systems Engineering from The Ohio State University. 